\title{
APPROACH OF CO-MICRONIZATION IN SOLUBILITY ENHANCEMENT AND RELEASE PROFILE OF RAPID DISPERSIBLE TABLETS OF TOLFENAMIC ACID
}

\author{
*Chinmay Anand ${ }^{1}$, Gali Vidyasagar ${ }^{2}$ Manisha Rajmane $^{3}$, Vijay Agrawal ${ }^{3}$, Shubhangi Sawant ${ }^{4}$ \\ ${ }^{1}$ Department of Pharmacy, JJT University, Jhunjhunu, India \\ ${ }^{2}$ Veerayatan Institute of Pharmacy, Jakhania, Kutch, India \\ ${ }^{3}$ Research \& Development, Elder Pharmaceuticals, Navi Mumbai, India \\ ${ }^{4}$ S. P. College of Pharmacy, Pune, India \\ *Corresponding Author's E-mail: chinmay_anand@yahoo.com
}

Received 02 Oct 2012; Review Completed 21 Oct 2012; Accepted 01 Nov 2012, Available online 15 Nov 2012

\begin{abstract}
Tolfenamic Acid is an orally and parenterally administered Non - steroidal anti-inflammatory drug belonging to the fenamate group. Dissolution is the rate limiting step for the absorption of Tolfenamic acid due to its poor solubility. In order to improve the solubility of drug and its dissolution rate concept of co-micronization of Tolfenamic acid with diluents and surfactants was studied in present study. Tolfenamic acid was co-micronized with microcrystalline cellulose and surfactants as sodium Lauryl sulfate. One reference formulation was also manufactured with conventional method using non-micronized Tolfenamic acid with surfactants. The formulation was than evaluated for various physical and analytical properties of rapid dispersible tablets. Results obtained showed that there was a significant increase in dissolution rate of drug in first 5 minutes of time interval as compare to reference formulation. The wetting and dispersion properties of formulation also found superior as compare to reference formulation.

Keywords: Tolfenamic Acid, Particle Size Reduction, Co-micronization, Sodium Lauryl Sulfate, Dissolution Profile, Rapid Dispersible Tablets

Abbreviations: TA shows Tolfenamic Acid, IP: Indian Pharmacopoeia, BP: British Pharmacopoeia, RMG: Rapid Mixer Granulator, FFBE: Flat Face Beveled Edge, mm: millimeter, mg: milligram, RPM: Round per minute, RH: Relative Humidity, QS: Quantity as sufficient, w/w: weight by weight.
\end{abstract}

\subsection{INTRODUCTION}

The concept of rapid dispersible, fast dissolving, quick dissolving, and orodispersible tablets dosage forms have acquired great importance in recent years due to their unique properties and advantages over other available dosage forms. ${ }^{1,2}$ In the recent years, great interests in the modification of drug release by using various methods such as solid dispersion, particle size reduction, micronization, direct compaction method, melt granulation techniques, solvent deposition inclusion complexation methods were adopted in formulation. ${ }^{3}$ The basic goal behind all of such innovations include developing a suitable formulation with rapid release of poorly water-soluble drugs. ${ }^{4}$

Nearly one-third of drugs in development are water insoluble and one-half fail in trials because of underprivileged pharmacokinetics. ${ }^{5}$ Tolfenamic Acid also falls in the same category, the basic challenge in formulation of Tolfenamic acid is its poor solubility. ${ }^{6}$ Tolfenamic Acid is an orally and parenterally administered Non - steroidal anti-inflammatory drug belonging to the fenamate group. ${ }^{7}$ Since the Tolfenamic acid is poorly water soluble drug so the dissolution is the rate limiting step for the absorption of drug. The Tolfenamic acid was originally formulated as hard gelatin capsules probably because of difficulties in preparing tablet being a reasonable size and rapid disintegration of active in compressed dosage form, with suitable size that can be easily swallowed by patients. ${ }^{8}$ There are various approaches for improvement of release profile by application of various techniques such as solid dispersion, ${ }^{9}$ by using surfactants, ${ }^{10}$ and size reduction ${ }^{8}$ of Tolfenamic acid is reported in the various literature and patents.

Nowadays Co- micronization of active with specific excipients becomes interesting approach to enhance the release profile of poor water soluble compounds. ${ }^{11,12,13}$ Tolfenamic acid is insoluble in nature, therefore in present study efforts were made to improve the release profile of active and to formulate rapid dispersible tablets of Tolfenamic acid by using novel concept of comicronization.

\subsection{MATERIALS}

Tolfenamic Acid was a gift sample from Elder Pharmaceuticals Ltd, Navi Mumbai, India. Aspartame and Flavor Vanilla was a gift sample from Cadila Pharmaceuticals Limited, Ahmadabad, India. Microcrystalline cellulose, Sodium Lauryl sulfate, Povidone, Mannitol, and sodium starch glycolate were obtained from commercial sources.

\subsection{METHODS}

The basic aim of the study was to enhance the release profile of Tolfenamic acid by using co-micronization concept. Approximately $1 \%$ of disintegrants was added to make dispersion and wetting of tablets but it did not had a greater impact on dissolution enhancement. The details of formulations were summarized in the table- 1 . 
Table 1: Formulation details of Rapid Dispersible Tablets of TA

\begin{tabular}{|l|c|c|c|c|}
\hline \multicolumn{1}{|c|}{ Ingredients } & \multicolumn{4}{c|}{ Quantity available in each tablets (mg/tabs) } \\
\hline & $\mathbf{A - 1}$ & $\mathbf{A - 2}$ & $\mathbf{A - 3}$ & $\mathbf{A - 4}$ \\
\hline Intra-granular & & & & 100.00 \\
\hline Tolfenamic Acid & 100.00 & 100.00 & 81.250 & 80.000 \\
\hline Microcrystalline Cellulose & 80.000 & 80.000 & -- & 1.250 \\
\hline Sodium Lauryl Sulfate & 1.250 & 1.250 & 2.500 & 2.500 \\
\hline Povidone (PVP K-30) & 2.500 & 2.500 & QS & QS \\
\hline Purified Water & QS & QS & & 45.000 \\
\hline Extra-granular & & & 2.500 & 2.500 \\
\hline Mannitol & 45.000 & 45.000 & 1.250 & 1.250 \\
\hline Sodium Starch Glycolate & 2.500 & 2.500 & 5.000 & 5.000 \\
\hline Magnesium Stearate & 1.250 & 1.250 & 2.500 & 2.500 \\
\hline Aspartame & 5.000 & 5.000 & $\mathbf{2 4 0 . 0 0}$ & $\mathbf{2 4 0 . 0 0}$ \\
\hline Flavor Vanilla & 2.500 & 2.500 & $\mathbf{2 4 0 . 0 0}$ & \\
\hline Tablet Weight in mg & $\mathbf{2 4 0 . 0 0}$ & &
\end{tabular}

3.1 Solubility Enhancement of Tolfenamic Acid and its evaluation

Total four formulations were designed to evaluate the effect of the co-micronization on the dissolution and dispersion properties of finished product. Formulation A-1 was manufactured with non micronized Tolfenamic acid as reference to check the impact of co-micronization on the various physico-chemical properties of formulation.

3.1.1 Manufacturing of Co-micronization blend ${ }^{24}$

Table 2: Preparation of Co-micronization blend for solubility enhancement

\begin{tabular}{|c|l|l|l|l|}
\hline Formulation & \multicolumn{1}{|c|}{$\mathbf{A - 1}$} & \multicolumn{1}{|c|}{$\mathbf{A - 2}$} & \multicolumn{1}{c|}{$\mathbf{A - 3}$} & \multicolumn{1}{c|}{ A-4 } \\
\hline Processing & $\begin{array}{l}\text { Simple mixing of un- } \\
\text { micronized TA with MCC } \\
\text { and SLS for reference }\end{array}$ & $\begin{array}{l}\text { Micronization of TA } \\
\text { and mixing with MCC } \\
\text { and SLS }\end{array}$ & $\begin{array}{l}\text { Co-micronization of } \\
\text { TA and MCC. }\end{array}$ & $\begin{array}{l}\text { Co-micronization of } \\
\text { TA, with MCC \& SLS. }\end{array}$ \\
\hline
\end{tabular}

\subsubsection{Physical evaluation of Co-micronization blend}

The evaluation of micronized mixtures of Formulation A-1 to A-4 was confirmed for particle size of TA mixture. The particle size was evaluated by using Malvern Mastersizer 2000. The average particle size which was the mean particle size of $90 \%$ (d-0.9) of particle in sample was recorded for evaluation. $^{14}$

\subsection{Manufacturing of Granules ${ }^{25}$}

Co-micronized blend of Tolfenamic acid was mixed in rapid mixer granulator (HSMG-10, Kevin Machinery) with slow impeller speed (75 RPM) for 10 minutes, PVP K-30 was dissolved in distilled water to give a binder concentration of $6.0 \% \mathrm{w} / \mathrm{v}$. To granulate, the binder was added slowly over five minutes through a glass funnel to control the flow rate. The resultant material was wet massed through the required sieve. Granules were vacuum dried using vacuum dryer (Shree Engineering) at $55^{\circ} \mathrm{C}$ for $150-180$ minutes. In addition to the temperature and the duration of the drying process, the moisture content and flow rate of the circulating air could affect granule strength and therefore to standardize, the amount of granules in each tray-dried was kept within an approximate range of $600-900 \mathrm{~g}$. The residual granule moisture content was determined by loss on drying. Granules were stored in double polythene bags until use to prevent moisture loss / gain. The dried granules than blended with extra granular excipients as per the given details of formulation in table - 1 using bin blender (Solace
The co-micronization of Tolfenamic Acid and diluents as per the given details of formulation in Table -2 was done by using Air-jet mill (Shree Engineering). Total three cycle of micronization was completed to insure the proper particle size reduction of blend. Micronization of formulation A-1 was not done; but sifting of Tolfenamic acid (nonmicronized) of Formulation A-1 was done through \#60 meshes to insure the uniformity of Tolfenamic acid in blend.
Engineering) at 12 RPM for 10 minutes. The blends were lubricated with Magnesium Stearate using bin blender at 12 RPM for 3 minutes.

\subsection{Manufacturing of Tablet ${ }^{25}$}

The compression of granules was completed by using Cadmach single rotary compression machine. $9.00 \mathrm{~mm}$ FFBE chrome plated punching tools was used to avoid any sticking problem during compression. The average turret speed during compression was also kept in range of $10-12$ RPM. In preliminary work, problems with uncontrolled moisture sorption occurred in granules during tabletting. Highly variable moisture contents made direct effect on physical properties of tablets. The relative humidity of the tabletting area monitored during compression of tablets. The higher humidity had significant effect on tablets properties, so a limit of $50 \% \mathrm{RH}$ was set as the maximum relative humidity at which tabletting was carried out.

\subsection{Physical Evaluation of Granules}

\subsubsection{Loss on drying ${ }^{15}$}

Loss on drying is the loss of weight expressed as percentage w/w resulting from water and volatile matter of any kind that could be driven off under specified conditions. The loss on drying was calculated by using equation,

$$
\% L O D=\frac{\text { Weight of solvent in sample }}{\text { Total weight of initial sample }} \text { X100 }
$$


Anand et al

Journal of Drug Delivery \& Therapeutics; 2012, 2(6), 29-36

Approximately 2.0 gms of dried granules were placed on aluminum disk of IR moisture balance. The loss on drying was recorded at $105^{\circ} \mathrm{C}$ for 10 minutes of time interval.

\subsubsection{Tapped and Untapped Density ${ }^{15,16}$}

Un-tapped and tapped density was determined by placing a graduated cylinder containing a known mass of drug on a mechanical tapper apparatus which was operated for fixed number of taps $(\sim 100)$ until a powder bed volume had reached the minimum. The ratio of mass (weight) to volume is known as the untapped bulk density of material. The bulk density of a powder depends on particle size distribution. The equation for determining the bulk density and tapped density is,

$$
\begin{aligned}
\mathrm{pb} & =\frac{\mathrm{M}}{\mathrm{Vp}} \\
\mathrm{pt} & =\frac{\mathrm{M}}{\mathrm{Vt}}
\end{aligned}
$$

Where, ' $\rho b$ ' is untapped bulk density, ' $\rho t$ ' is tapped density , ' $\mathrm{M}$ ' is weight of sample in grams, ' $\mathrm{Vp}$ ' is final volumes of powder in $\mathrm{cm}^{3}$, ' $\mathrm{Vt}$ ' is tapped volume of powder in $\mathrm{cm}^{3}$.

\subsubsection{Compressibility Index ${ }^{15,16}$}

The compressibility index of the granules was determined by Carr's index. The Carr's index was determined from the tapped density and poured density (bulk density) as per the formula given below,

$$
\text { Carr's Index }(\%)=\frac{\text { Tapped Densit }- \text { Bulk Density }}{\text { Tapped Density }} \text { X100 }
$$

\subsubsection{Hausner Ratio ${ }^{16}$}

Hausner Ratio was determined from the ratio of tapped density to bulk density using formula given below.

$$
\text { Hausner Ratio }=\frac{\text { Tapped Density }}{\text { Bulk Density }}
$$

Flow of granules was evaluated by using interpretation between Hausner Ratio and carr's index as shown in table 3

Table 3: Interpretation by Hausner Ratio.

\begin{tabular}{|c|c|c|}
\hline Hausner's Ratio & Interpretation & Equivalent Carr's Index \\
\hline 1.25 & Good flow & $20 \%$ \\
\hline$>1.25$ & Poor flow & $33 \%$ \\
\hline
\end{tabular}

\subsubsection{Angle of repose $\mathrm{e}^{15,16}$}

Angle of repose of samples were measured by employing fixed height method, the specific amount of sample was poured through the funnel from the height of $2 \mathrm{~cm}$. The diameter of pile formed was measured and angle of repose was calculated by using following formula,

$$
\theta=\frac{\mathrm{h}}{\mathrm{r}}
$$

Where, ' $\theta$ ' is angle of repose, ' $h$ ' is height, and ' $r$ ' is radius. The flow properties of granules were than interoperated by using table as shown in table -4 .

Table - 4: Interpretation of angle of repose

\begin{tabular}{|l|c|}
\hline \multicolumn{1}{|c|}{ Flow Properties } & Angle of Repose \\
\hline Excellent & $25-30$ \\
\hline Good & $31-35$ \\
\hline Fair-aid not needed & $36-40$ \\
\hline Passable-may hang up & $41-45$ \\
\hline Poor-must agitate, vibrate & $46-55$ \\
\hline Very poor & $56-65$ \\
\hline
\end{tabular}

\subsection{Physical Evaluation of Tablets}

\subsubsection{Appearance}

Appearance of tablets was evaluated by taking twenty tablets of each formulation and visually checked for any discoloration or surface roughness on the core surface of tablet formulation.

\subsubsection{Weight Variation of tablets ${ }^{16,17}$}

Weight variation of tablets was calculated by weighing 20 tablets individually and determining the average weight. Tablet meets the test if not more than two of the individual weights deviate from percentage limits of $7.5 \% .^{17}$

\subsubsection{Hardness ${ }^{16,18}$}

The hardness of six tablets was determined using the Erweka type hardness tester and the average values were calculated for each formulation trials.

\subsubsection{Thickness ${ }^{18}$}

The Thickness of the tablets was determined by using Digital vernier calipers (Mitutoyo, Japan). Six tablets were used, and average values were calculated for each formulation trials.

\subsubsection{Friability ${ }^{16}$}

It was intended to determine the loss of mass under defined conditions. The friability of uncoated tablets was determined by using Electro lab Friability Apparatus. The 20 pre weighed tablets were paced in friability apparatus and tested for the effects of abrasion and shock by utilizing a plastic chamber that revolves at $25 \mathrm{rpm}$ dropping the tablets at a distance of six inches with each operation for 100 revolutions. The tablets are then de dusted and reweighed. The percentage for friability than calculated using following formula,

$$
\text { Friability }(\%)=\frac{\text { Initial weight of Tablets }- \text { Final weight of Tablets }}{\text { Initial weight of Tablets }} \times 100
$$


Anand et al

Journal of Drug Delivery \&
oeia the limit for friability

As per the Indian pharmacopoeia the limit for friability tablets should not be more than $1 \% \mathrm{w} / \mathrm{w} .{ }^{17}$ The values for both Hardness \& Friability can together indicate the mechanical strength of tablet. ${ }^{19}$

\subsubsection{Disintegration Time}

Disintegration is defined as time required by tablet to completely disintegrate and disappear from the basket. Disintegration time of tablets was evaluated as per the specification of disintegration time of dispersible and Orodispersible tablets in British pharmacopoeia. ${ }^{20}$ Disintegration was carried out by using $600 \mathrm{ml}$ of disintegration media mentioning the temperature at $15^{\circ} \mathrm{C}-$ $25^{\circ} \mathrm{C}$ in disintegration basket. ${ }^{18}$ Disintegration discs were not used during disintegration. The use of discs during disintegration reduces discrimination between good and bad formulations since the palpable residue on the mesh would not pass through without applying pressure and thus violating the principle of fluid penetration and particle separation. $^{21}$

\subsubsection{In vitro dispersion Time and Fineness of Dispersion}

Fineness of dispersion is specified in the specification of dispersible tablets.$^{20,22}$ This taste is required to check the
Therapeutics; 2012, 2(6), 29-36

fineness and smoothness of dispersion of tablets. The same concepts were applied to correlate the dispersion of tablets in vivo by using $\mathrm{pH} 6.8$ phosphate buffer. The in vitro dispersion time was observed by placing one tablet in a beaker containing $50 \mathrm{ml}$ of $\mathrm{pH} 6.8$ phosphate buffer at $37^{\circ} \mathrm{C}$ $+1^{0} \mathrm{C}$, the time required to disperse the tablets was determined. ${ }^{23}$ The same dispersion was passed through a sieve screen with a nominal mesh aperture of $710 \mathrm{~mm}$ to confirm the fineness of dispersion.

\subsubsection{Wetting Time and Water Absorption Ratio}

Water absorption ratio of tablet was evaluated by using aqueous solution of Methylene Blue. It is also an indicating method to evaluate the disintegrating mechanism of tablets. ${ }^{18}$ Absorbent cotton soaked with $0.04 \%$ aqueous solution of methylene blue was placed in a Petri dish, the tablets was placed flat on the surface of cotton, and the time required to change the color of whole tablets to blue was measured as water absorption time. Total six tablets were used for the investigation of water absorption time and mean of water absorption time was calculated. ${ }^{19}$

Water absorption ratio (WAR) was calculated by using the pre weight and post weight of tablet used for wetting time evaluation by using following equation,

$$
\text { WAR }(R)=\frac{\text { Weight of wetted tablets }- \text { Weight of dry Tablets }}{\text { Weight of dry Tablets }} \times 100
$$

\subsection{Analytical Evaluation of Tablets}

\subsubsection{Assay of drug content in Tablets ${ }^{20,22}$}

The analysis for drug content of formulation was developed based on monograph of Tolfenamic acid in British pharmacopoeia. $^{20}$

\section{Standard Preparation}

Weigh accurately \& transfer about $150 \mathrm{mg}$ of Tolfenamic acid in $100 \mathrm{ml}$ volumetric flask, dissolve it in $50 \mathrm{ml}$ of 0.1 $\mathrm{M} \mathrm{NaOH} \&$ dilute up to mark with $0.1 \mathrm{M} \mathrm{NaOH}$. Dilute 1 $\mathrm{ml}$ of the solution to 100 with $0.1 \mathrm{M} \mathrm{NaOH}$.

\section{Sample Preparation}

The assay of each formulation was evaluated by taking twenty tablets and crushing the tablets by using Petri dish. $240 \mathrm{mg}$ equivalent weight of powdered Tolfenamic acid was taken in to a $100 \mathrm{ml}$ volumetric flask. Add $80 \mathrm{ml}$ of 0.1 $\mathrm{M} \mathrm{NaOH}$. Shake for 30 minutes, dilute to $100 \mathrm{ml}$ with 0.1 $\mathrm{M} \mathrm{NaOH}$. Filter, discarding the first few $\mathrm{ml}$ of the filtrate and dilute $1 \mathrm{ml}$ of this solution to $100 \mathrm{ml}$ with $0.1 \mathrm{M} \mathrm{NaOH}$. Measure the absorbance of sample and standard preparation at $289 \mathrm{~nm}$ using $0.1 \mathrm{M} \mathrm{NaOH}$ as the blank with UV Spectrophotometer (Shimadzu). Calculate content of Tolfenamic acid per tablets, by following formula;

\section{$\%$ drug content $=\frac{\text { Test Absorbance X Standard Concentration }}{\text { standard Absorbance X weight of SD taken }} \mathrm{X}$ dilution factor X 100}

\subsubsection{In-vitro drug release kinetics ${ }^{20,22}$}

In-vitro dissolution studies of all formulation were evaluated for the release profile of formulation. The basic objective of formulation was to develop the rapid disintegrating formulations, so release profile at various time intervals such as $5,10,15,30,45$, and 60 minutes were analyzed for the evaluation of release kinetics.

USP dissolution apparatus Type-II Paddle, 100 RPM

Dissolution Medium

Phosphate Buffer pH 7.2

Temperature

$1000 \mathrm{ml}$,

Sampling Times (minutes)

$37 \pm 0.50 \mathrm{C}$

45 , and 60

\section{Preparation of Dissolution Medium}

(C) 2011, JDDT. All Rights Reserved
Take $250 \mathrm{ml}$ of ethanol $96 \%$ and dilute to $1000 \mathrm{ml}$ with Phosphate Buffer pH 7.2.

\section{Preparation of Phosphate Buffer pH 7.2}

Dissolve $40.8 \mathrm{~g}$ of Potassium dihydrogen phosphate in 1500 $\mathrm{ml}$ of distilled water and adjust $\mathrm{pH}$ to 7.2 with $40 \% \mathrm{NaOH}$ and then dilute to $4500 \mathrm{ml}$ with water.

\section{Preparation of Standard solution}

Weigh accurately \& transfer about $100 \mathrm{mg}$ of Tolfenamic acid in a $500 \mathrm{ml}$ volumetric flask. Dissolve in $250 \mathrm{ml} 0.1 \mathrm{M}$ $\mathrm{NaOH} \&$ dilute up to mark with $0.1 \mathrm{M} \mathrm{NaOH}$. Dilute $1 \mathrm{ml}$ of resulting solution to $25 \mathrm{ml}$ with $0.1 \mathrm{M} \mathrm{NaOH}$.

\section{Dissolution Procedure ${ }^{8}$}

Dissolution of tablets was initiated by placing one tablet in each of six vessels containing $1000 \mathrm{ml}$ dissolution medium, using paddle apparatus at $100 \mathrm{rpm}$ for 60 minutes. $5 \mathrm{ml}$ of 
the sample solution was withdrawn from the dissolution beaker as per the given time interval and replacing the same volume by addition of dissolution media. The absorbance of sample solution and standard solution was measured by using UV Spectrophotometer (Shimadzu) at the maximum about $289 \mathrm{~nm}$ using $0.1 \mathrm{M} \mathrm{NaOH}$ as blank.

\subsection{RESULT AND DISCUSSION}

4.1 Physical evaluation of Co-micronization blend
The average particle size which is the mean particle size of 90\% (d-0.90) of particle in sample was recorded for evaluation ad tabulated in the table -5 .

\section{Discussion}

The average particle size of reference formulation (unmicronized) formulation A-1 was $161.625 \mu \mathrm{m}$, and average particle size of micronized and co-micronized blend for formulation A-2, A-3, and A-4 were approx $10 \mu \mathrm{m}$, which was reflecting an effective particle size reduction using Air jet mill.

Table - 5: Particle size distribution after micronization

\begin{tabular}{|c|c|c|c|}
\hline Formulation & Average Particle Size $(\mathbf{d - 0 . 9 0 )}$ in $\boldsymbol{\mu m}$ & Particle Size (d-0.50) in $\boldsymbol{\mu m}$ & Particle Size (d-0.10) in $\boldsymbol{\mu m}$ \\
\hline $\mathbf{A - 1}$ & 161.625 & 53.675 & 9.621 \\
\hline $\mathbf{A - 2}$ & 10.926 & 6.256 & 3.256 \\
\hline $\mathbf{A - 3}$ & 9.856 & 6.958 & 3.125 \\
\hline $\mathbf{A - 4}$ & 10.214 & 5.935 & 2.968 \\
\hline
\end{tabular}

\subsection{Physical Evaluation of Granules}

The various physical evaluation for granules of formulation A-1 to A-4 is summarized in table - 6 .

Table - 6: Physical properties of granules $(n=3)$

\begin{tabular}{|l|l|l|l|l|}
\hline Physical Properties & $\mathbf{A - 1}$ & $\mathbf{A - 2}$ & $\mathbf{A - 3}$ & $\mathbf{A - 4}$ \\
\hline $\begin{array}{l}\text { Qty of water uptake during } \\
\text { granulation }(\mathrm{ml})\end{array}$ & Nil & 10 & 14 & 17 \\
\hline Loss on drying (\%w/w) & $1.42 \pm 0.312$ & $1.513 \pm 0.031$ & $1.640 \pm 0.050$ & $1.600 \pm 0.020$ \\
\hline Bulk density $(\mathrm{gm} / \mathrm{ml})$ & $0.55 \pm 0.010$ & $0.500 \pm 0.017$ & $0.523 \pm 0.006$ & $0.530 \pm 0.010$ \\
\hline Tapped density $(\mathrm{gm} / \mathrm{ml})$ & $0.683 \pm 0.015$ & $0.637 \pm 0.012$ & $0.627 \pm 0.021$ & $0.623 \pm 0.006$ \\
\hline Carr's Index $(\%)$ & $19.500 \pm 1.407$ & $21.481 \pm 1.283$ & $16.448 \pm 1.874$ & $14.968 \pm 1.793$ \\
\hline Hausner's Ratio & $1.242 \pm 0.022$ & $1.274 \pm 0.021$ & $1.197 \pm 0.027$ & $1.176 \pm 0.025$ \\
\hline Angle of Repose & $33.33 \pm 0.58$ & $36.667 \pm 0.577$ & $31.667 \pm 0.577$ & $30.333 \pm 0.577$ \\
\hline
\end{tabular}

\section{Discussion}

The additional quantity of water during granulation was noted in all four formulations, 10,14 , and $17 \mathrm{ml}$ additional uptake of water was required in formulation A-2, A-3, A-4. This might be due to increased surface area of particle due to co-micronization of Tolfenamic acid, and Tolfenamic acid with diluents. The same tendency of additional drying was observed during drying of granules, the loss on drying for formulation $\mathrm{A}-3 \& \mathrm{~A}-4$ was 1.60 and $1.64 \% \mathrm{~W} / \mathrm{W}$, as compare to loss on drying of formulation $\mathrm{A}-1$, and $\mathrm{A}-$ $2 ; 1.42$ and $1.513 \% \mathrm{w} / \mathrm{w}$.

Angle of repose was evaluated to confirm the flow of granules, the values of angle of repose was found in the range of $30-36$ indicating a fair to good flow of granules. The effect of micronization clearly reflecting in the compressibility index of granules, which is the basic requirement of compression, the co-micronization processing of formulation A-3 and A-4 showed good compressibility index in the range of $15-16$. The same observation also reflecting in housner's Ratio of granules.

So on the basis of various physical properties of granules; it was clearly indicating the justified selection of intra granular diluents such as microcrystalline cellulose and wet granulation of co-micronized granules to avoid any weight variation problem, die filling problem, and flow problem during compression of tablets.

\subsection{Physical evaluation of tablets}

The various physical evaluation for tablets of formulation A-1 to A-4 is summarized in table - 7 .

Table 7: Physical evaluation of tablets

\begin{tabular}{|c|c|c|c|c|}
\hline Evaluation Parameters & A-1 & A-2 & A-3 & A-4 \\
\hline Appearance & \multicolumn{4}{|c|}{ Off-white colored, $9.0 \pm 0.1 \mathrm{~mm}$, round flat faced tablet } \\
\hline Weight Variation $(\%)$ & $241.56 \pm 2.35$ & $241.34 \pm 1.93$ & $241.01 \pm 2.46$ & $240.85 \pm 2.29$ \\
\hline Hardness (Newton) $n=6$ & $28.67 \pm 2.50$ & $30.00 \pm 2.10$ & $33.33 \pm 2.16$ & $35.00 \pm 1.26$ \\
\hline Thickness $(\mathrm{mm}) \mathrm{n}=6$ & $3.20 \pm 0.01$ & $3.18 \pm 0.02$ & $3.20 \pm 0.02$ & $3.19 \pm 0.02$ \\
\hline Friability $(\% \mathrm{w} / \mathrm{w})$ & 0.65 & 0.68 & 0.72 & 0.69 \\
\hline Disintegration (Seconds) & $15-20$ & $18-22$ & $15-20$ & $17-22$ \\
\hline Dispersion (Seconds) $n=3$ & $50.67 \pm 1.15$ & $43.67 \pm 1.53$ & $43.67 \pm 1.00$ & $40.00 \pm 3.00$ \\
\hline Wetting Time (Seconds) $n=3$ & $65.00 \pm 3.00$ & $55.00 \pm 2.00$ & $43.67 \pm 1.53$ & $40.00 \pm 2.00$ \\
\hline Water Absorption Ratio & 53.17 & 55.79 & 61.82 & 66.08 \\
\hline
\end{tabular}




\section{Anand et al Discussion}

The appearance of tablets found good without any significant defects (figure - 1). Weight variation data for all the formulations batches indicated no significant difference in the weight of individuals tablets from the average value and weight variation were found to be within limits. The value of hardness friability of tablet showed good strengths in all formulation, which is an essential parameter for formulation of rapid dispersible tablets. The thickness of tablets was also within limit.

Disintegration time for all formulation was in range between 15 and 22 seconds, which is required to formulate ideal rapid dispersible tablets. There was some significant difference observed in dispersion and wetting time of formulation, the dispersion time and wetting time was higher for formulation A-1 and A-2 as compare to formulation A-3 and A-4. The rapid dispersion and wetting reflects the effect of co-micronization of blend during granulation stage. The co-micronization of blend was increasing the surface area of compressed blend during dispersion and wetting. The dispersion and wetting time was lowest for the formulation A-4, indicating the clear impact of wetting properties of sodium Lauryl sulfate in formulation. The co-micronization of sodium Lauryl sulfate with active and diluents increasing the wetting properties of granules. Same phenomenon of rapid dispersion and wetting reflects in water absorption ratio of formulation A-4. The water absorption ratio for formulation A-4 and A-3 was very less as compare to A-1 and A-2. So there is clear impact of co-micronization in enhancement of physical properties of formulations. Since the present study was focused on the enhancement of release profile of formulation, still there were possibilities of enhancing the dispersion and wetting time by using more concentration of superdisintegrants. The diagrammatic presentation of dispersion and wetting of tablets is shown in figure -2 and 3.

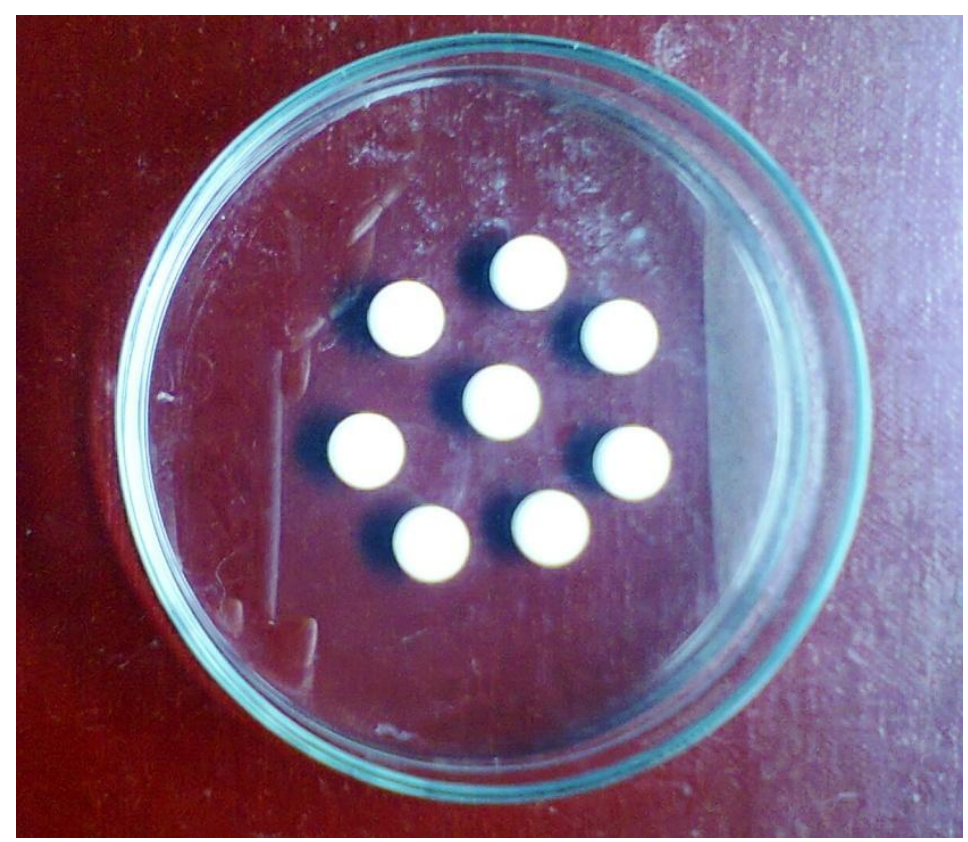

Figure 1: Appearance of Tablets

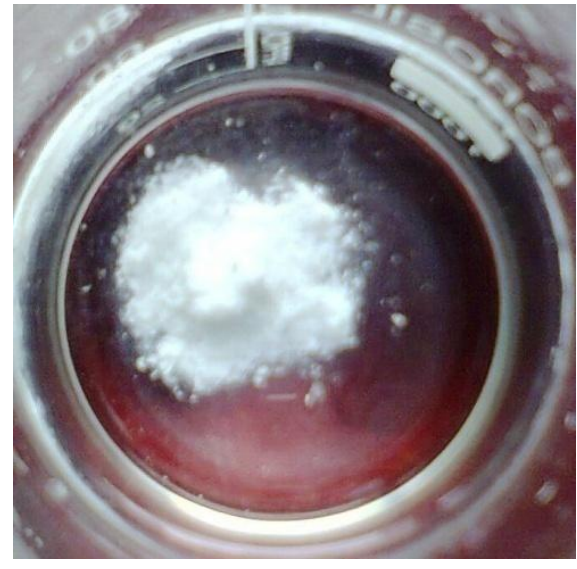

Figure 2: Dispersion of Tablets

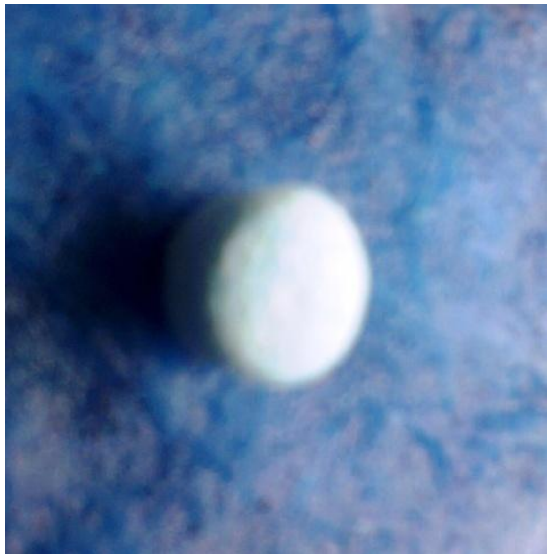

Figure 3: Wetting of Tablets

\subsection{Analytical Evaluation of Tablets}

The assay of drug content and in vitro drug release profile for tablets of formulation A-1 to A-4 is summarized in table -8 and 9. 
Table 8: Assay of drug content in tablets

\begin{tabular}{|c|c|c|c|c|}
\hline Evaluation Parameters & A-1 & $\mathbf{A - 2}$ & $\mathbf{A - 3}$ & A-4 \\
\hline Drug Content $(\%) \mathrm{n}=3$ & $100.97 \pm 1.75$ & $100.30 \pm 1.97$ & $100.80 \pm 1.73$ & $100.33 \pm 1.63$ \\
\hline Content Uniformity (\%) $\mathrm{n}=10$ & Passed & Passed & Passed & Passed \\
\hline
\end{tabular}

\section{Discussion}

The drug content of tablets and content uniformity of tablets for all formulation A-1 to A-4 was well within the limits.
There was no significant variation observed due to comicronization and simple mixing of blend at granulation stage.

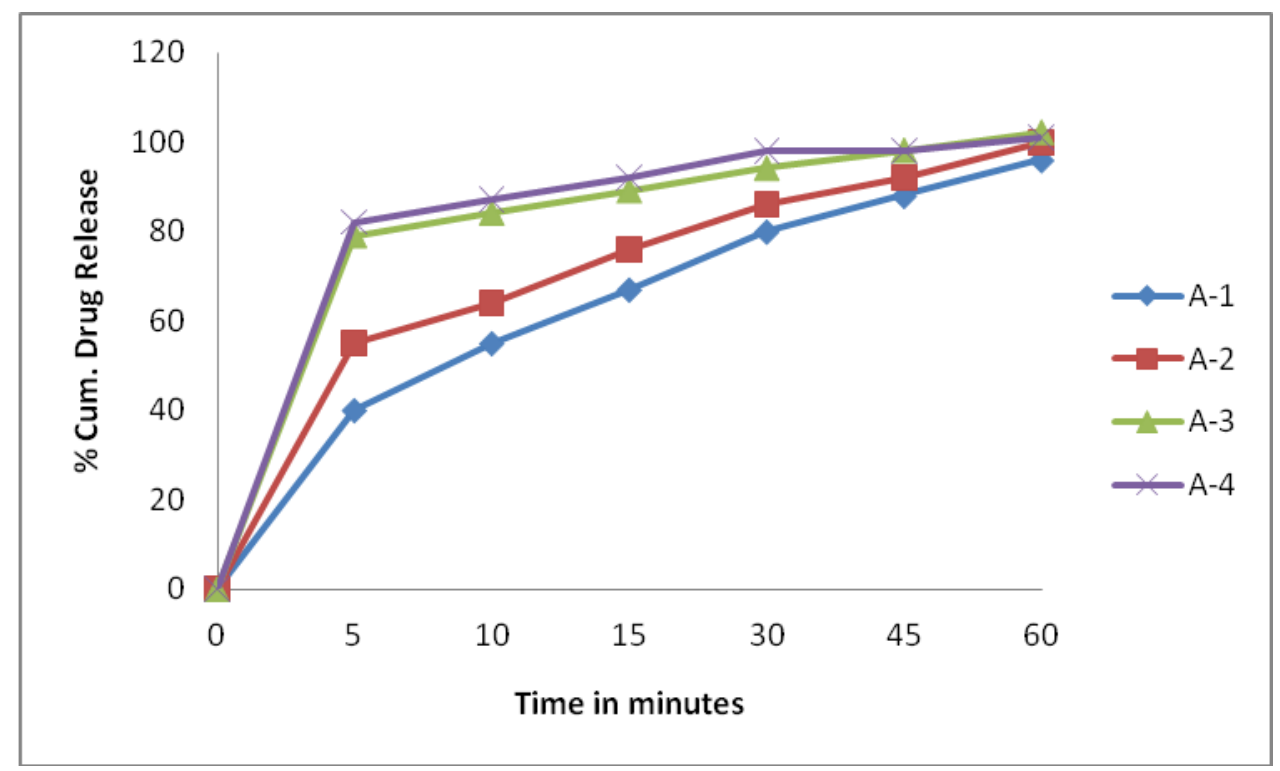

Figure 4: Effect of co-micronization on release profile of formulations

\section{Discussion}

The rate of drug release was found to be related to the comicronization process of the formulations. The release of formulations A-1, A-2, A-3, A-4 is 40, 55, 79, and $82 \%$ respectively. The release profile after 15 minutes for formulation A-1, A-2, A-3, A-4 is 67, 76, 89, and $92 \%$ respectively. There was no significant difference observed after 30 minutes of dissolutions studies. Among all formulation A-3 and A-4 showed more than $90 \%$ release of active within 15 minutes of dissolution. The rapid release of about $80 \%$ of medicament was observed in formulation A1, and A-2, which differentiated it from the remaining formulation such as A-1 and A-2. The effect of comicronization on the release profile of formulation also shown in figure - 4. The effect of micronization also reflecting in formulation A-2, but the co-micronization of active with diluents was fulfilling the basic aim of development of rapid dispersible tablets of Tolfenamic acid.

\section{REFERENCES}

1. Liang AC, Chen LH, "Fast Dissolving Intraoral Drug Delivery Systems," Exp. Opin. Ther. Patents, 2011, 11(6), 981-986.

2. Borsadia S, O'Halloran D, Osborne JL, "Quick Dissolving Films-A Novel Approach to Drug Delivery", Drug Delivery Technology, 2003, 3(3).

3. Vikas A Saharan, Vipin Kukkar, Mahesh Kataria, Manoj Gera, Pratim K Choudhury, "Dissolution Enhancement of Drugs Part II: Effect of Carriers," International Journal of Health Research, 2009 September, 2(2), 207-223.

(C) 2011, JDDT. All Rights Reserved

\section{CONCLUSION}

On the basis of various physical and analytical evaluation of formulation the rapid dispersion and wetting of formulation can easily achieved by simple incorporation of micronization of active with diluents. The co-micronization showed a promising effect in the particle size reduction of Tolfenamic acid and providing more surface area in enhancement of wetting and dispersion properties of formulations. The comparative evaluation of formulation A1 (as reference formulation without micronization of active) proved the concepts of co-micronization in the Tolfenamic acid rapid dispersible tablets. The rapid release of formulation which was the basic requirement of rapid dispersible tablets also achieved by using co-micronization approach during manufacturing of granules.

\section{ACKNOWLEDGEMENT}

We are very grateful to Elder Pharmaceuticals for providing Tolfenamic Acid and Cadila Pharmaceuticals Limited for providing excipients. Authors wish to thank the faculty of Pharmacy JJT University and Veerayatan Institute of Pharmacy.
4. Lecomte F, Siepmann J, Walther M, MacRae RJ, Bodmeier R, "Blends of enteric and GIT-insoluble polymers used for film coating: physicochemical characterization and drug release patterns, Journal of Controlled Release, 2003, 89, 57-71.

5. Savic R, Eisenberg A, Maysinger D, "Block copolymer micelles as delivery vehicles of hydrophobic drugs: Micellecell interactions," J Drug Target, 2006, 14, 343-355.

6. Pedersen SB, "Biopharmaceutical aspects of Tolfenamic acid," Pharmacol Toxicol. 1994; 75 Suppl 2, 22-32. 
7. EMEA, Committee for veterinary Medicinal Products Tolfenamic Acid Summary Report, EMEA/ MRL/ 183/ 97 Final April 1997.

8. Gebhard KE-Hansen, Karen B, Lars H, Soren Boles P, 2000 "Rapid Release Tablets comprising Tolfenamic Acid or A Pharmaceutically Acceptable Salt Thereof," US Patent 6036975.

9. Pia Thybo, Jakob Kristensen, Lars Hovgaard, "Characterization and Physical Stability of Tolfenamic Acid PVP K 30 Solid Dispersions," Pharmaceutical Development and Technology, 2007, Vol. 12, No. 1, 43-53.

10. Raunio O, Turakka, L, "The solubility of Tolfenamic acid in surfactant solutions." Pharm. Ind., 1982, 44, 750-752.

11. Colin A, J Hecq L Camus, S Cuart, L Grislain, M Galiay, (2012) "Co-micronization scale-up study of poorly watersoluble pharmaceutical API: from Precellys-24 to laboratory ball mill," [Last cited on 2012 Sep 06].www.aapsj.org.pdf.

12. Spence JK, Bhattachar SN, Wesley JA, Martin PJ, Babu SR, "Increased dissolution rate and bioavailability through comicronization with microcrystalline cellulose," Pharm Dev Technol. 2005, 10(4), 451-60.

13. B Idzior-Walus, J Sieradzki, W Rostworowski, A Zdzienicka, E Kawalec, J Wojcik, A Żarnecki, G Blane, "Effects of comicronised fenofibrate on lipid and insulin sensitivity in patients with polymetabolic syndrome X," European Journal of Clinical Investigation, Volume 30, Issue 10, October 2000, 871-878.

14. Betz G, "The role of drug solubility in formulation development." In: Rong Liu, ed. Water-insoluble Drug Formulation, CRC; Press Taylor and Francis Group, 2008,615, 19-9c22.

15. Subrahmanyam CVS, Thimmasetty J, Shivanand KM, Vijayendra Swamy SM, Laboratory manual of industrial pharmacy, Vallabh Prakashan, 2006, New Delhi.

16. Banker GS, Anderson NR. Tablets. In: Lachman L, Lieberman H.A, Kanig JL, The Theory and Practice of Industrial Pharmacy, 3rd Ed, Varghese publishing house, Bombay. 1987, 293-345.

17. Indian Pharmacopoeia, (2010): Ministry of Health and Family welfare, Government of India, Controller of Publication, New Delhi, India.

18. Yayoi Kawano, Akihiko Ito, Masanaho Sasatsu, Yoshiharu Machida, and Hiraku Onishi, "Preparation and Evaluation of Taste Masked orally disintegrating tablets with granules made by wet granulation method." The Pharmaceutical Society of Japan, 2010, Vol 130 (12), 1737-1742.

19. Jyoti Singh and Meenakshi Bajpai, "Effect of superdisintegrants in the formulation of taste-masked orodispersible tablets of Tizanidine HCl," Journal of Pharmacy Research 2011,4(7), 2175-2178.

20. British Pharmacopoeia 2012 Edition, (2012): London, UK.

21. Wells JI, "Encyclopedia of Pharmaceutical Technology." Swarbrick J, Boylan, JC (Eds.), 1996, 401.

22. European Pharmacopoeia, $7^{\text {th }}$ Ed., 2010. Council of Europe, Strasbourg, France.

23. Bi YX, Sunada H, Yonezawa Y, Danjo K, "Evaluation of rapidly disintegration tablets by direct compression method." Drug Develop Ind Pharm, 1999, 25, 571-81.

24. Kaur Jaspreet, Singh Gurpreet, Saini Seema, Rana AC, "Particle Size Reduction Of Aceclofenac by using Surfactants And Micronization For Nanocarrier Entrapment", Journal of Drug Delivery \& Therapeutics; 2012, 2(5), 42-44.

25. Dinkar Sharma, Reetika Chopra And Neena Bedi, "Development And Evaluation of Paracetamol Taste Masked Orally Disintegrating Tablets Using Polymer Coating Technique”, Int. J. Pharm. Pharm. Sci, Vol 4, Suppl 3, 129134. 